\title{
Two genes encoding proteins with similarities to rubredoxin and rubredoxin reductase are required for conversion of dodecane to lauric acid in Acinetobacter calcoaceticus ADP1
}

\author{
Walter Geissdorfer, S. Christian Frosch, $†$ Gerhard Haspel, Sabine Ehrt \\ and Wolfgang Hillen
}

Author for correspondence: Wolfgang Hillen. Tel: +499131858081. Fax: +499131858082.

Lehrstuhl für

Mikrobiologie, Institut für Mikrobiologie, Biochemie und Genetik der FriedrichAlexander Universităt Erlangen-Nürnberg, Staudtstraße 5, 91058 Erlangen, FRG

\begin{abstract}
Mutants of Acinetobacter calcoaceticus ADP1 unable to grow on dodecane, but retaining the ability to grow on lauric acid were isolated after ethylmethanesulphonate (EMS) treatment. This growth deficiency was complemented by a clone from a gene library constructed from chromosomal DNA of the wild-type strain. The complementing DNA mapped in a gene encoding a polypeptide with homology to rubredoxins. The deduced putative rubredoxin amino acid sequence is more similar to related proteins from Gram-positive bacteria than to the Pseudomonas oleovorans rubredoxin involved in alkane oxidation. An adjacent gene encodes a protein with similarity to rubredoxin reductase from Pseudomonas oleovorans and related NAD(P)-dependent reductases. Disruption of the rubredoxin-encoding gene by insertion of a $\mathrm{Km} / \mathrm{lacZ}$ cassette rendered the resulting strain unable to grow on dodecane or hexadecane. This demonstrates that these genes are necessary for alkane degradation. Transcriptional fusion of lacZ to the rubredoxinencoding gene led to low level constitutive $\beta$-galactosidase expression, whereas the fusion oriented in the opposite direction was not expressed.
\end{abstract}

Keywords: Acinetobacter calcoaceticus, alkane oxidation, rubredoxin reductase

\section{INTRODUCTION}

Many strains of Acinetobacter calcoaceticus widely distributed in natural habitats are able to utilize n-alkanes as sole carbon and energy source via the $\omega$-oxidation pathway (Asperger \& Kleber, 1991). The primary attack on the chemically inert alkane is achieved by hydroxylation involving either a cytochrome $\mathrm{P} 450$ as shown for $A$. calcoaceticus EB104 or a rubredoxin-dependent hydroxylase (Asperger \& Kleber, 1991; Leahy \& Colwell, 1990; Claus et al., 1980). P450-dependent alkane hydroxylases also occur in Candida tropicalis (Sanglard \& Loper, 1989), for example. The paradigm for a rubredoxin-dependent alkane hydroxylase is that in Pseudomonas oleovorans (van Beilen et al., 1992; Eggink et al., 1988, 1990).

We chose $A$. calcoaceticus ADP1, also known as BD413

†Present address: Institut für Genetik, Universităt Bielefeld, 33501 Bielefeld, FRG.

The GenBank accession number for the nucleotide sequence data reported in this paper is $\mathbf{Z 4 6 8 6 3}$.
(Juni \& Janik, 1969; Patel et al., 1975), to study alkane degradation, because it is a mutant of BD4 with a reduced capsule offering the possibility to study involvement of capsular material in alkane degradation in the future. Furthermore, the utilization of aromatic hydrocarbons has been well studied in that strain (DiMarco \& Ornston, 1994; Shanley et al., 1994) and has profited from the natural competence of the strain, making genetic constructions feasible which would require considerable technical developments in other strains.

In this article we describe the construction and complementation of an $A$. calcoaceticus ADP1 mutant deficient in dodecane utilization by a gene encoding a protein with high similarity to rubredoxins, which is located next to a gene with high similarity to $\mathrm{NAD}(\mathrm{P})$-dependent reductases from various organisms. We prove by insertional inactivation that the isolated genes are essential for growth on dodecane and hexadecane.

\section{METHODS}

Bacterial strains and plasmids. $A$. calcoaceticus strains and plasmids used and constructed in this work are summarized in 
Table 1. A. calcoaceticus strains and plasmids used and constructed in this study

\begin{tabular}{|lll|}
\hline Strain/plasmid & \multicolumn{1}{c|}{$\begin{array}{c}\text { Relevant } \\
\text { genotype/properties }\end{array}$} & Source/reference \\
\hline ADP1/BD413 & alk & \\
WH363 & alk & Juni \& Janick (1969) \\
WH361 & alk::lac $Z, \mathrm{Km}^{\mathbf{R}}$ & $\begin{array}{l}\text { This study } \\
\text { This study }\end{array}$ \\
WH362 & alk::lacZ, $\mathrm{Km}^{\mathbf{R}}$ & This study \\
pWH1274 & Shuttle vector & Hunger et al. (1989) \\
pWH1266 & Shuttle vector & Hunger et al. (1989) \\
pWH660+- & Shuttle vectors & This study \\
pKOK6.1 & Source of lac $Z / K \mathrm{~K}^{\mathbf{R}}$ cassette & Kokotek \& Lotz (1989) \\
pWH964 & alk::lacZ, Km & This study \\
pWH965 & alk::lac $Z, \mathrm{Km}^{\mathbf{R}}$ reverse orientation & This study \\
pWH1721 & alk-complementing & This study \\
pWH979 & alk-complementing & This study \\
\hline
\end{tabular}

Table 1. A. calcoaceticus ADP1 is able to grow on dodecane as sole carbon source. Escherichia coli XL1 blue (obtained from Stratagene) and DH5 $\alpha$ (Hanahan, 1983) were used as cloning hosts. pBluescript SKII \pm were obtained from Stratagene and used for isolating nested deletions and for sequencing. pKOK6. 1 (Kokotek \& Lotz, 1989) was kindly provided by W. Lotz, Erlangen, FRG.

Transformations. E. coli XL1 blue was transformed as described by Hanahan (1983) or by electroporation (Stratagene). $A$. calcoaceticus ADP1 was transformed as described by Hunger et al. (1989), making use of its natural competency.

Media and growth conditions. Unless noted otherwise, $A$. calcoaceticus and $E$. coli strains were grown in Luria Broth (LB; Sambrook et al., 1989) at $28^{\circ} \mathrm{C}$ and $37^{\circ} \mathrm{C}$, respectively. Selective media for ampicillin resistance contained $200 \mathrm{mg}$ ampicillin $\mathrm{l}^{-1}$. Selective growth of $A$. calcoaceticus was in minimal medium supplemented with 'metals 44' (Breuil et al., 1978) solidified with $1.5 \%(\mathrm{w} / \mathrm{v})$ agar in Petri dishes, which were kept inverted with a $3 \mathrm{~cm}^{2}$ Whatman filter paper soaked with $0.2 \mathrm{ml}$ dodecane placed inside the lid, so that the substrate was provided by diffusion through the gas phase. $\beta$-Galactosidase activities expressed in different media, as detailed in the text, were determined from three independently grown cultures according to Miller (1972).

Mutagenesis of $\boldsymbol{A}$. calcoaceticus ADP1. Fresh LB $(20 \mathrm{ml})$ was inoculated with $20 \mu \mathrm{l}$ of an overnight culture and grown to an $\mathrm{OD}_{600}$ of 0.5 . Then $180 \mu$ l ethylmethanesulphonate (EMS) was added. After initial mixing the culture was kept for $3 \mathrm{~h}$ at $28{ }^{\circ} \mathrm{C}$ without shaking. The viability count dropped to $60 \%$ during treatment. A portion $(50 \mu \mathrm{l})$ of culture was used to inoculate $4 \mathrm{ml}$ of fresh $\mathrm{LB}$, which was grown to an $\mathrm{OD}_{600}$ of $0 \cdot 14$. The bacteria were then spread on minimal medium plates with $350 \mathrm{mg}$ lauric acid $\mathrm{I}^{-1}$ and incubated for $3 \mathrm{~d}$ at $28^{\circ} \mathrm{C}$. After purification by restreaking, single colonies from these plates were screened for lack of growth on dodecane minimal plates.

Preparation of DNA. Small-scale isolation of plasmid DNA from $A$. calcoaceticus and $E$. coli was done by the boiling lysis method (Crouse et al., 1983). Large-scale preparation of plasmid DNA from $E$. coli was performed by the Brij-Doc method (Ausubel et al., 1989). Chromosomal DNA was isolated according to Sambrook et al. (1989).

Complementation of A. calcoaceticus WH363. Total DNA from $A$. calcoaceticus ADP1 was digested with $0 \cdot 1 \mathrm{U}$ Sau3AI $\mu \mathrm{g}^{-1}$ for $2 \mathrm{~min}$ at $37^{\circ} \mathrm{C}$ and ligated with BamHI-digested, dephosphorylated pWH1266 (Sambrook et al., 1989). This ligation mixture was used to transform $A$. calcoaceticus WH363. Selection was on LB plates with ampicillin and colonies were replica-plated to minimal plates with dodecan and ampicillin. The plasmids obtained were used to transform E. coli. They were then reisolated and used to transform $A$. calcoaceticus WH363.

Southern blotting. Restricted total DNA $(8 \mu \mathrm{g})$ or restricted plasmid DNA ( $20 \mathrm{ng}$ ) were run on a $1 \%$ agarose gel and blotted to positively charged nylon membrane (Southern, 1975). The probe was prepared using the nick translation kit for biotin-7dATP (obtained from BRL). A PhotoGene kit (obtained from BRL) was used for detection of signals.

DNA sequencing. DNA sequencing of both strands was done using the nested deletion method on an ALF automated sequencer according to the recommendations of the manufacturer (Pharmacia). Sequences were analysed using the UwGCG software package (Devereux et al., 1984).

\section{RESULTS}

\section{Isolation of $A$. calcoaceticus ADP1 mutants deficient in alkane oxidation}

Using the mutagenesis protocol described in the Methods section, 2650 candidates able to grow on minimal medium with lauric acid were obtained and screened for inability to grow on dodecane. The former property indicates that degradation of fatty acids by $\beta$-oxidation is not affected by the mutations. The screen yielded 27 candidates with a negative phenotype on solid agar plates. Candidate WH363 has a reversion frequency of approximately $10^{-7}$ indicating that the defect for growth on dodecane may be due to a point mutation. Therefore, this mutant was used for complementation by a gene library.

\section{Complementation of A. calcoaceticus WH363 for growth on dodecane}

Partially Sau3A-digested total DNA from $A$. calcoaceticus ADP1 was inserted into BamHI-cleaved pWH1266 and used to transform $A$. calcoaceticus WH363. The trans- 
formants were selected for growth on LB with ampicillin and replica-plated on minimal medium with ampicillin and dodecane. Four candidates forming large colonies on these plates were further analysed. After preparation and passage of their plasmids through E. coli and retransformation of $\mathrm{WH} 363$, one of these plasmids was found to confer the ability to grow on dodecane minimal plates. Preparation and restriction analysis of the recombinant plasmid, called pWH1721, revealed a $17 \mathrm{~kb}$ insertion. When compared to wild-type ADP1 transformed with the vector pWH1266, WH363 transformed with pWH1721 grew to give larger colonies on dodecane minimal plates, indicating that the insertion may have a positive gene dosage effect for growth on dodecane under these conditions.

\section{Deletion analysis of the complementing insert}

We have constructed a new shuttle vector for $A$. calcoaceticus and $E$. coli to allow deletional analysis for complementation to be combined with the nested deletion approach for sequencing. For this purpose, pBluescript SKII \pm was partially digested with PvuII and ligated with the PvuII-HincII fragment from pWH1266 carrying the Acinetobacter ori (Hunger et al., 1989). The resulting plasmids, called pWH660士, contained the respective fragment inserted in the PvuII site at position 529 in the lac $Z$ reading frame. $\mathrm{pWH} 660$ + was used to insert a $12 \mathrm{~kb}$ BamHI fragment from pWH1721 resulting in pWH979, which complemented strain WH363 for growth on dodecane. Unidirectional deletions of the insert with a mean spacing of $1 \mathrm{~kb}$ were generated and tested for complementation of WH363 for growth on dodecane as sole carbon source. The smallest fragment complementing WH363 for growth on dodecane minimal plates contained $3 \cdot 2 \mathrm{~kb}$.

\section{Nucleotide sequence of the complementing DNA}

Nested deletions of the second smallest complementing insert of $3.7 \mathrm{~kb}$ were obtained, and the DNA was sequenced on both strands. Analysis of the sequence revealed two ORFs with similarities to genes involved in alkane degradation of Ps. oleovorans (see below). The genetic organization of that region is shown in Fig. 1. Two of the nested deletions mapped in this region are also shown in Fig. 1. Deletion of the right-hand $600 \mathrm{bp}$ still yielded a complementing fragment, whereas deletion of the right-hand $1430 \mathrm{bp}$ did not. Thus, the ability to complement the dodecane growth defect is encoded in the left half of the respective DNA. The nucleotide sequence of the DNA between the FspI and HaeII sites is shown in Fig. 2, along with the deduced amino acid sequences of two ORFs. The ORFs scored positively for elevated protein coding probability in the TESTCODE program and in a codon preference analysis using the codon usage table derived from Acinetobacter genes (Fickett, 1982; Pearson \& Lipman, 1988; White et al., 1991).

Restriction sites deduced from the sequence are shown in Fig. 1 and were used to confirm the origin of the complementing DNA from the chromosomal ADP1
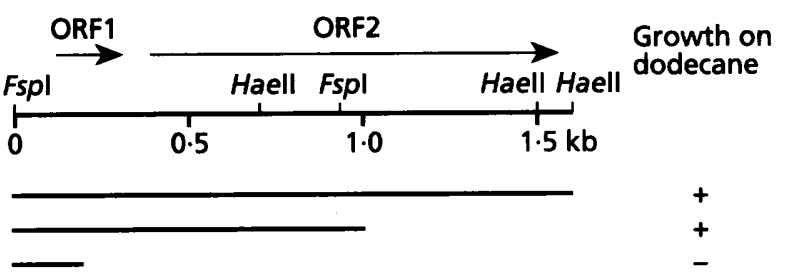

Fig. 1. Restriction map, genetic organization and complementation capacity of 1530 bp Acinetobacter DNA. ORF1 and ORF2 are indicated by arrows. Relevant restriction sites are shown. Fragments obtained after nested deletions of the originally cloned DNA are indicated by lines below the map (see Results for details). + indicates the ability of strain WH363 transformed with plasmids containing the DNA indicated by the respective lines to grow on dodecane.

DNA by Southern blotting using the FspI fragment as a probe (data not shown). DNA between the FspI sites and an $800 \mathrm{bp} \mathrm{HaeII} \mathrm{fragment} \mathrm{corresponded} \mathrm{with} \mathrm{fragments}$ of the same size in the chromosomal DNA. Thus, the region between the FspI and HaeII sites represents a contiguous piece of the ADP1 DNA (Fig. 1). Probing with BstNI and Sau96I fragments from pWH979, including the DNA shown in Fig. 1, yielded fragments of different size from the plasmid than from the chromosome. This result indicates that disruptions of the insert must have occurred within $1200 \mathrm{bp}$ upstream and $500 \mathrm{bp}$ downstream of the region shown in Fig. 1.

Both ORFs on the complementing DNA are preceded by putative ribosome binding sites, as judged by sequence comparison with other Acinetobacter genes. ORF1 contains the sequence GGAG (commencing at position 113 in Fig. 2) spaced 6 nucleotides from the putative start codon ATG. ORF2 does not contain a putative ribosome binding site in front of the first ATG (commencing at position 312 in Fig. 2), but instead, the sequence GGAG precedes the second ATG (commencing at position 372 in Fig. 2) with a spacing of 7 nucleotides.

\section{Similarities of the amino acid sequences encoded by ORF1 and ORF2 with known proteins}

Sequence similarities were searched in the GenBank, EMBL and Swissprot databases. The protein encoded by ORF1 is homologous to all rubredoxins present in these databases. A sequence alignment is shown in Fig. 3. The highest similarity was found with a rubredoxin from Clostridium thermosaccharolyticum (Meyer et al., 1990) with $63 \%$ identical residues. An identity of $60 \%$ was found for rubredoxin from Chlorobium thiosulfatophilum (Wooley \& Meyer, 1987) and 57\% identity with the one from the archaeon Pyrococcus furiosus (Blake et al., 1991). These results reiterate the view that rubredoxins are highly conserved proteins. A rubredoxin involved in alkane oxidation has been characterized in Ps. oleovorans (Kok et al., 1989). It has twice the molecular mass of the other rubredoxins, resulting probably from a gene duplication. The functional part is located in the C-terminal half, which has $59 \%$ identity with the product of ORF1. 
1

91

361

991

1081

1171

1351

1441

1531

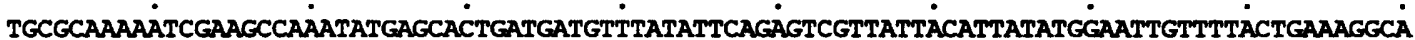

GCTGAAGCGAACTTATCAGGTTGGMGATCAAATGAAAAAGTATCAATGTATCGTTTGTGGTTGGATTTATGATGAAGCCGAAGGCTGGC $\begin{array}{lllllllllllllllllll}M & K & K & Y & Q & C & I & V & C & G & W & I & Y & D & E & A & E & G & W\end{array}$ CACAAGACGGCATTGCACCAGGGACAAAATGGGAGATATTCCTGATGACTGGACTTGCCCCTGACTGCG C्CGTTTCAAAAGTTGATTTTG

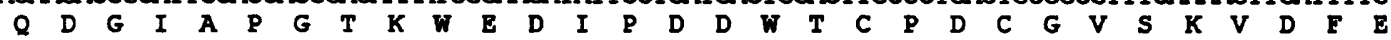
AAATGATCGAAGTTTAATCGGTATTTCAAAAGACCATGTCCATGAAACATGGTCTTTTTAATTTAATCTTAGTTTTTATTACCTTACTAC M I E V *

gGMGATAATAATGCACCCAATCGTCATTATCGgATCAGGAATGGCAGGTTATACCCTTGCTCGTGAATTTCGCAAGCTTAATCCTGAAC $\begin{array}{lllllllllllllllllllllllllll}M & H & P & I & V & I & I & G & S & G & M & A & G & Y & T & L & A & R & E & F & R & K & I & N & P & E & H\end{array}$ ATGAACTTGTCATGATTTGTGCTGACGATGCAGTGAATTÁtGCAAAACCAACCTTATCTAATGCGCTTTĆTGGCAACAAÁGCACCACAAC

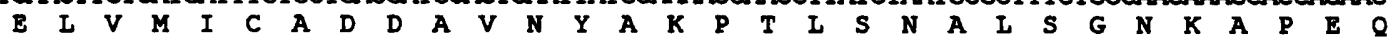

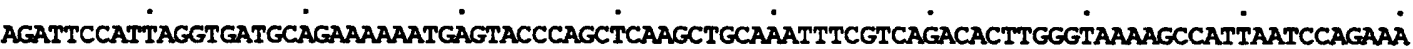
$\begin{array}{llllllllllllllllllllllllllllllllllll}I & P & L & G & D & A & E & K & M & S & T & Q & L & K & L & Q & I & S & S & D & T & W & V & K & A & I & N & P & E & T\end{array}$ CTCATGAATTAAAATTAGAAAAAAATGGTCAGGAAACGATTCAGCCCTATTCCAAACTGG'TTCTGGCTGTAGGCGCCAATCCAACCCGTT $\begin{array}{llllllllllllllllllllllllllllllllll}H & E & L & K & L & E & K & N & G & Q & E & T & I & Q & P & Y & S & K & L & V & I & A & V & G & A & N & P & T & R & I\end{array}$ TAGCCATTGCCGGTGATGGTAGTGATGATATTCATGTGGTGAACTCTCTTATCGATTATCGCGCCTTTCGTGAAAATCTTGCAAAACGTC $\begin{array}{lllllllllllllllllllllllllllllllll}A & I & A & G & D & G & S & D & D & I & H & V & V & N & S & I & I & D & Y & R & A & F & R & E & N & L & A & K & R & Q\end{array}$ AAGATAAGCGTGTTGTCATTCTAGGTGCAGGTCTTATTGG̈TTGTGAATTTGCCCATGATTTACAGCATACTGGGCATCAGGTGACAGTCA

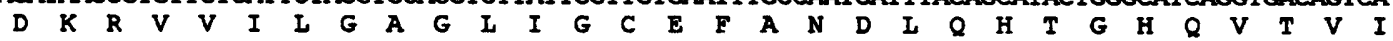
TCGACTTGTCTCCTCGCCCACTGGGTCGTCTATTACCTGCGCATATTGCAAGATGCTTTTCAGAAAATCTĠGACAAAGCGTATTCACTTTG $\begin{array}{llllllllllllllllllllllllllllll}D & L & S & P & R & P & L & G & R & L & L & P & A & H & I & A & D & A & F & Q & K & I & \mathbf{W} & R & K & R & I & H & F & V\end{array}$ TACTTTCAACCACAGTAGAAAAAGTATCTAAAATTAACGÄTGGTCAAGATTATGCTGTCACACTGGCAAA்TGGTCAGACǴCTAGTGGCCG $\begin{array}{llllllllllllllllllllllllllllll}\mathbf{L} & \mathbf{S} & \mathbf{T} & \mathbf{T} & \mathbf{V} & \mathbf{E} & \mathbf{K} & \mathbf{V} & \mathbf{S} & \mathbf{K} & \mathbf{I} & \mathbf{N} & \mathbf{D} & \mathbf{G} & \mathbf{Q} & \mathbf{D} & \mathbf{Y} & \mathbf{A} & \mathbf{V} & \mathbf{T} & \mathbf{L} & \mathbf{A} & \mathbf{N} & \mathbf{G} & \mathbf{Q} & \mathbf{T} & \mathbf{L} & \mathbf{V} & \mathbf{A} & \mathbf{D}\end{array}$ ACATTGTTTTATCTGCAATCGGATTACAACCAAACATTGATCTGGCAAAACACGCAGGCGTGCATACCAGTCGAGGTATTTTGACTAATAं

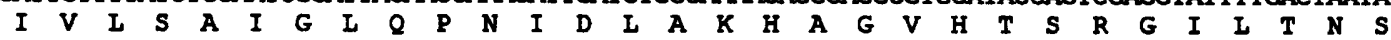
GCCTCCTAGAAACCAACCTTGAAGACATCTATGCAATAGGCGACTGTGCTGAAGTTAATGGAACCTTGCTCCCCTACGTGATGCCGATCA

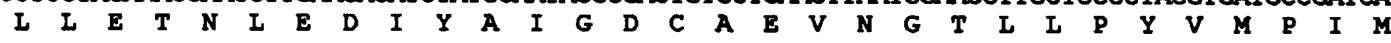
TGCAGCAGGCCCGCGCCCTCGCGAAAACCTTGAGTGGTGAAACAACACATGTTCACTATCCTGCCATGCCAGTTGCTGTAAAAACGCCTG $\begin{array}{llllllllllllllllllllllllllllllll}Q & Q & A & R & A & I & A & K & T & L & S & G & E & T & T & H & V & H & \mathbf{Y} & \mathbf{P} & \mathbf{A} & \mathbf{M} & \mathbf{P} & \mathbf{V} & \mathbf{A} & \mathbf{V} & \mathbf{K} & \mathbf{T} & \mathbf{P} & \mathbf{A}\end{array}$ CAGCCCCGCTCACCGTACTTCCTGTACCTGTGGATGTAGATGTAAACTGGGAAACAGAAGATTTGAAGÁTGGTATGCTTGCCAAAGCTA $\begin{array}{llllllllllllllllllllllllllllll}\text { A } & \text { P } & \text { L } & \text { T } & \text { V } & \text { L } & \text { P } & \text { V } & \text { P } & \text { V } & \text { D } & \text { V } & \text { D } & \text { V } & \text { N } & \mathbf{W} & \mathbf{E} & \mathbf{T} & \mathbf{E} & \mathbf{E} & \mathbf{F} & \mathbf{E} & \mathbf{D} & \mathbf{G} & \mathbf{M} & \mathbf{L} & \mathbf{A} & \mathbf{K} & \mathbf{A} & \mathbf{I}\end{array}$ TCGACAATACCGATACACTCAGAGGTTTTGTACTATTAGG'TGCTACGGCG̈GTAAACAGCGCCTGACACTCACCAAACTGGTTCCAGACT $\begin{array}{llllllllllllllllllllllllllllll}D & N & T & D & T & I & R & G & F & V & I & \text { L } & G & A & T & A & G & K & Q & R & I & T & I & T & K & I & V & P & D & I\end{array}$ TGATTCCCGCACAGCTTTAÄGGTTTAAATAGCAAGGACATTCATCTGAGTGTCCTTTTTÁGGAACGGATCATAAAATGAiTAGCGCT I P A Q I *

Fig. 2. Nucleotide and deduced amino acid sequence of genes encoding rubredoxin and rubredoxin reductase of $A$. calcoaceticus ADP1. The encoded amino acid sequences are shown using one letter abbreviations under the nucleotide sequence. Putative ribosome binding sites are indicated in underlined bold print.

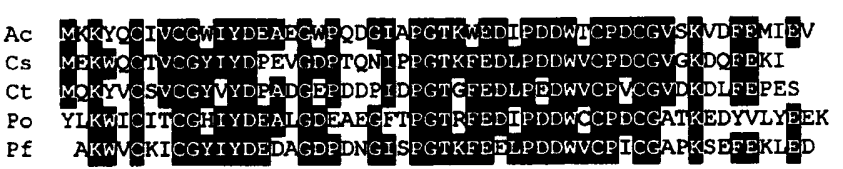

Fig. 3. Homology of rubredoxin sequences from various microorganisms. When at least three identical amino acid residues occur at a given position they are shown in reversed-out print. Abbreviations: Ac, A. calcoaceticus (this work); Cs, Clostridium thermosaccharolyticum (Meyer et al., 1990); Ct, Chlorobium thiosulfatophilum (Woolley \& Meyer, 1987); Po, Ps. oleovorans (C-terminal 55 amino acids are shown) (Kok et al., 1989); Pf, Py. furiosus (Blake et al., 1991).
The protein encoded by ORF2 is homologous to four oxidoreductases involved in the degradation of hydrocarbons. The sequence alignment is shown in Fig. 4. The identities of residues are: $28 \%$ with terpredoxin reductase from $P$ seudomonas spp. involved in $\alpha$-terpineol degradation (Peterson et al., 1992); $27 \%$ with rubredoxin reductase from $P_{\text {s. oleovorans involved in alkane degradation (Eggink }}$ et al., 1990); $26 \%$ with putidaredoxin reductase from $P$ s. putida involved in camphor degradation (Peterson et al., 1990 ); and $25 \%$ with the ferredoxin reductase of the toluene dioxygenase system from Ps. putida (Zylstra et al., 1989). Thus, we propose that ORF2 encodes the rubredoxin reductase involved in alkane degradation in $A$. calcoaceticus ADP1. 
(a) EAD-binding site

AC ....MHPIVIIGSG AGYTIAREFRKLNPEHELVMICADDAVNYAKP ILSNALSGNKAPEQIPLGDAEKMSTQLK PS MGERRDTTVIVGAGHAGTAAAF LLREFGYHGRVLLLSAETQHPYQRPPLSKEYLLAQHSTPSL. LKGKDSYARAD PO ..... MAIVVUGAGTAGVNAAFWLRQYGYKGEIRIFSRESVAPYQRP L SKAELTSEIAESAVPLKPEGFYTNNN Pp1. MNANDNVVIVGTGIAGVEVAFGLRASGWEGNI RLVGDATVIPHHIPPL SKAYLAGKATAESLYLRT PDAYAAQN Pp2 ... ATHVAIIGNGVGGFTTAQALRAEGEEGRISLIGDEPHLPYDRPSLSKAVLDGSLERPPI . LAEADWYGEAR

AC LQISSDTWVKAINPETHELKLEKNGQETIQPYSKLVLAVGANPTRLAIAGDG. . . SDDIHVVNSLIDYRAFRENL PS IELCLQDDVLSITPASRQVKS . . . SQG. SYTYDHLILATGSHPREM. . . . ATLGQADNLCYLSDWDDAGRIRQQL PO ITISINTPIVSIDVGRKIVSS . . KDGKEYAYEKLILA TPASARRLTCEGSELS . . GVCYLRSMEDAKNLRRKL Pp1 IQLLGGTQVIAINRDRQQVIL . . SDGRALDYDRLVLATGGRPRPLPVASGAVGKANNFRYLRTLEDAECIRRQL Pp2 IDMLTGPEVTALDVQTRTISL . . . DDGTTLSADAIVIATGSRARTMALPGSOLP . . . GVVTLRTYGDVQVIRDSW

NAD-binding site

AC AKRQDKRVVILGAGI IGCEFANDLQHTGHQVTVIDLSPRPLGRLLPAHIADAFQKIWRKR. IHFVLSTIVEKVSK Ps G. EASRIVVLGGGFIGLEIASSACKMGKHVTVIERAPRILSRVVSEAFATEIGDIHLGNGIELRLGEEVREVRR PO V. . ESASVVVLGGGVIGLEVASAAVGLGKRVTVIEATPRVMARVVTPAAANLVRARLEAEGIEFKLNAKLTSIK. Pp1 I. . ADNRLVVIGGGYIGLEVAATAIKANMHVTLLDTAARVLERVTAPPVSAFYEHLHREAGVDIRTGTQVCGEEM Pp2 T. . SATRLLIVGGGLIGCEVATTARKLGLSVT ILEAGDELLVRVLGRRIGAWLRGLLTELGVQVELGTGVVGF . .

FAD-binding site

AC INDGQDY. AVILANGQTLVADIVLSAIGLQPNIDLAKHAGVHTSRGI LTNSLLETNLEDIYA IGDCAEVNGTL . . PS CTSGVRVDAVFL SDGQLLECDMLVIGVGSEPRMELATAAGLACASGVIVDEHCHT SDPFISA IGDCVAVCPSPGH Po . GRNGHVEQCVLESGEEIQADLIVVGIGAIPELELATEAALEVSNGVUVDDQMCT SDTS IYA IGDCAMARNP EWG Pp1 STDQQKVTAVLCEDGTRLPADLVIAGIGLIPNCELASAAGLQVDNGIVINEHMQT SDPI IMAVGDCARFHSQLYD Pp2 . SGEGQLEQVMASDGRS FVADSALICVGAEPADQLARQAGLACDRGVIVDHCGATLAKGVFAVGDVASWPLRAGG

Ac ... LPYVMPIMQQARAIAKTLSGETTHVHYPA. . . . . . MPVAVKTPAAPLTVLPVPVDVDVNWETEEFEDGM PS QLPRRESVQNATEQARLVAARLSGRPVP PVQTPWFWSDQLQARINLAGERPAQGQVIVR. RYGGDKVSMLYLQDQ PO TMVRLET IHNANTHAQIVASS ICGTSTPAPT PPRFWSDLKGMALQGLGALKDYDKLVVAINNETLELEVLAYKQE Pp1 RWVRIESVPNALEQARKIAAILCGKVPRDEAAPWEWSDQYEIGLKMVGLSEGYDRI IVRGSLAQPDFSVFYLQGD Pp2 RR. SL ETYMNAQRQAAAVAAAIIGKNVSAPQIPVSWTEIAGHRMQMAGDIEGPGDFVSRGMPGSGAALLFRLQER

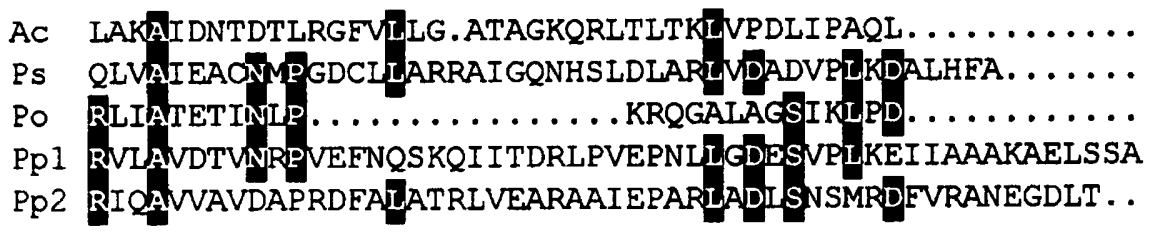

(b)

$\square \times \square \times G \times G \times \times G \times x \times \square \times x$

(1) P I V I I G S G A G Y T L A R E F 10aa M I C A D

(2) R V V I L A G L I G E F A D L 6aa V T V I D (c)

$\square \times \times \times \times \star \Delta \mathrm{G}$

T N I E D I Y A I G D

Fig. 4. Homology of $N A D(P)$-dependent reductases from different bacteria. (a) Five primary structures are aligned to give maximal identity of the residues. Three or more identical residues per position are given in reversed-out print. The two consensus sequences for the FAD-binding sites and the motif for the NAD-binding site are indicated above the sequences. Abbreviations: Ac, A. calcoaceticus (this work); Ps, Pseudomonas spp. (Peterson et al., 1992); Po, Ps. oleovorans (Eggink et al., 1990); Pp1, 2 = Ps. putida camphor- and toluene-specific reductases, respectively (Petersen et al., 1990; Zylstra et al., 1989). (b) Consensus sequence of the dinucleotide binding site (Wierenga et al., 1986). The sequence elements for (1) FAD- and (2) NAD-binding are shown below the consensus sequence. Symbols: $x$, any amino acid; $, K, R, H, S, T, Q$ or $N$; a, A, I, L, V, M or C; O, D or E. (c) Sequence of the motif found only in FAD-binding proteins (Eggink et al., 1990). The corresponding sequence of the ORF2-encoded protein is shown below the consensus sequence. Symbols: $x$, any amino acid; $\square, T$ or $M ; \Sigma_{3}, I, V, A$ or $L ; \star, Y, W$ or $F ; \Delta, I, V$ or $A$. 


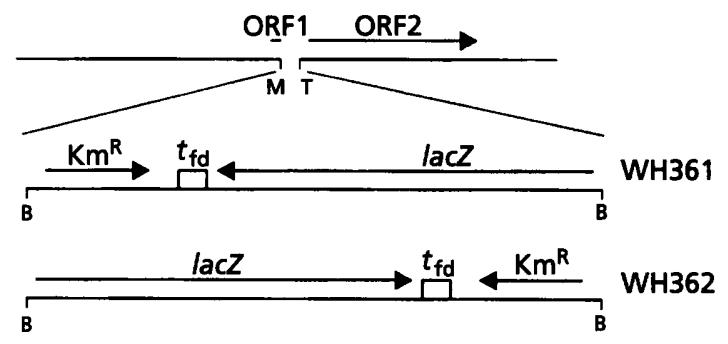

Fig. 5. Chromosmal organization of the insertion strains $\boldsymbol{A}$. calcoaceticus WH361 and WH362. For details of construction, see Results. The lacZ cassette of pKOK6.1 used here is the same as that described by Kokotek \& Lotz (1989), but lacZ is preceded by stop codons in each reading frame. $M, T$ and $B$ indicate the restriction sites of $\mathrm{MsCl}$, Tth1111 and BamHl, respectively.

\section{Chromosomal disruption of ORF1 and ORF2}

We have inactivated ORF1 and ORF2 on the ADP1 chromosome by insertion of a $\mathrm{Km}^{\mathrm{R}}$ cassette. For that purpose, the $2.1 \mathrm{~kb}$ DraI fragment from $\mathrm{pWH} 1721$ containing ORF1 and ORF2 was cloned into pBluescript SKII +, resulting in pWH963. This plasmid was cleaved with $M s c \mathrm{I}$ and $T$ th111I, and the $\mathrm{Km}^{\mathrm{R}}$ cassette was excised with BamHI from pKOK6.1 (Kokotek \& Lotz, 1989). The protruding ends of both fragments were filled in using Klenow polymerase and ligated to yield pWH964 and pWH965, which differ with respect to the orientation of the insertion. The inserts from both plasmids were excised with $S_{a c \mathrm{I}}$ and $A p a \mathrm{I}$ and transformed into $A$. calcoaceticus ADP1 using natural competency. Transformants were selected on LB plates supplemented with $15 \mathrm{mg}$ kanamycin $1^{-1}$. Integration of the cassettes into ORF1 and ORF2 was confirmed by Southern blotting. The resulting strains were called WH361 and WH362. The gene disruption is shown in Fig. 5.

\section{Alkane utilization phenotypes of the mutant A. calcoaceticus strains}

The mutant strain WH363 showed clear phenotypes when grown on solid media. We consistently observed no growth on dodecane, but growth like that of the wild-type on hexadecane and lauric acid. In liquid media, however, growth on dodecane was about the same for WH363 and wild-type (see Fig. 6). WH361 and WH362 containing the gene disruptions, in contrast, had a clear growth defect on both dodecane and hexadecane in liquid media, while growth on lauric acid was not affected. The same result was obtained on solid growth medium and establishes clearly that the genes isolated in this study are necessary for consumption of long chain length alkanes.

\section{Regulation of expression of the rubredoxin gene-lacZ transcriptional fusion}

The $\beta$-galactosidase activities determined in strains ADP1, WH361 and WH362 grown in minimal medium with $10 \mathrm{mM}$ succinate and in the same medium with $0.25 \mathrm{mM}$

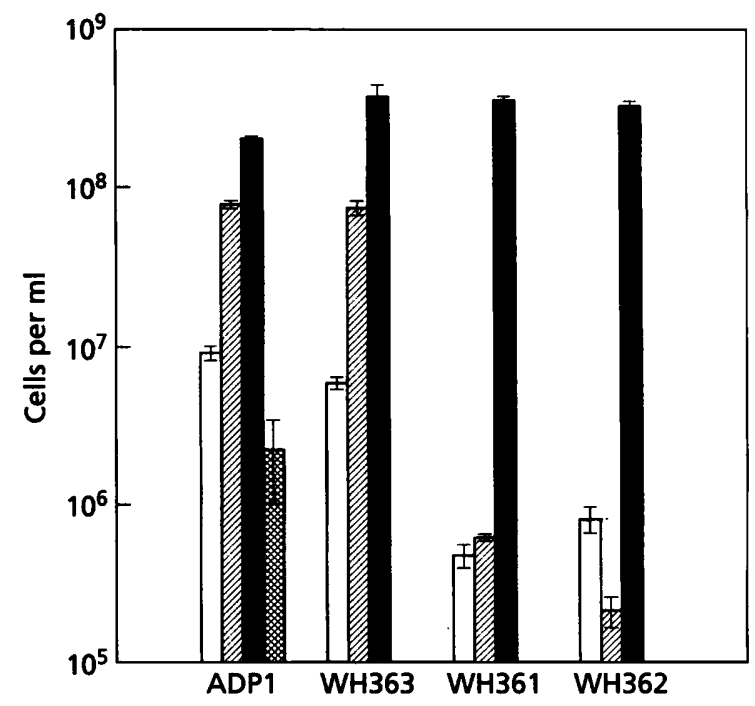

Fig. 6. Growth of A. calcoaceticus strains ADP1, WH363, WH361 and WH362 on $0.67 \mathrm{mM}$ dodecane $(\square), 0.5 \mathrm{mM}$ hexadecane $(\square)$ and $0.67 \mathrm{mM}$ lauric acid $(\square)$ as sole carbon source. 8 , no addition. The cultures $(50 \mathrm{ml})$ were incubated at $28^{\circ} \mathrm{C}$ and shaken at 180 r.p.m. Alkanes were added to the minimal medium in emulsified form after sonification. Titres of the cultures grown to saturation were determined by plating diluted aliquots on LB plates. Cultures were inoculated to a titre of $3 \times 10^{6}$ cells $\mathrm{ml}^{-1}$ and reached stationary phase after about $12 \mathrm{~h}$. Standard deviations were calculated from three titres determined after 27,31 and $50 \mathrm{~h}$ of incubation.

hexadecane are shown in Table 2. No lac $Z$ expression was found in ADP1 and WH361, in which the reporter gene is oriented in the opposite direction to the rubredoxin gene. A low level of constitutive expression was found in WH362. A similar result was obtained when succinate was replaced by ethanol as a potentially non-regulative carbon source (not shown).

\section{DISCUSSION}

It has been reported that some strains of $A$. calcoaceticus can grow on linear alkanes of variable length (Asperger \& Kleber, 1991). The strain ADP1 combines the ability to grow on dodecane with natural competency (Juni \& Janik, 1969), which seemed to be of advantage for identification of genes by complementation. The Southern analysis indicates consistency of restriction fragment lengths only between the FspI and HaeII sites (Fig. 1). Thus, only about $1600 \mathrm{bp}$ out of the $17 \mathrm{~kb}$ of the original insertion in the complementing plasmid turned out to be a continuous piece from the chomosome. This is most probably related to the mechanism of DNA uptake leading to the formation of mixed plasmids when gene libraries are transformed (for a detailed discussion, see Palmen et al., 1993). It is, therefore, advisable to use electroporation for DNA transfer, as has been described for non-competent $A$. calcoaceticus strains (Ehrt et al., 1994). Nucleotide sequencing of the insertion revealed two HaeII sites close together (positions 1498 and 1612 in 
Table 2. Expression of $\beta$-galactosidase in different $A$. calcoaceticus strains

\begin{tabular}{|lcr|}
\hline Strain & \multicolumn{2}{c|}{$\begin{array}{c}\beta \text {-Galactosidase activity (Miller Units) } \\
\text { after growth in minimal media supplemented with: }\end{array}$} \\
\cline { 2 - 3 } & Succinic acid (10 mM) & $\begin{array}{c}\text { Succinic acid (10 mM) } \\
+ \text { hexadecane (0.25 mM)* }\end{array}$ \\
\hline ADP1 & $-0.2 \pm 0.3$ & $-0.2 \pm 0.3$ \\
WH361 & $-0.1 \pm 0.3$ & $0.0 \pm 0.3$ \\
WH362 & $15.6 \pm 0.8$ & $14.2 \pm 0.8$ \\
\hline
\end{tabular}

* The medium was sonicated after the addition of hexadecane.

Fig. 2). The small HaeII fragment contains the last 16 codons of ORF2. Its presence in the chromosome has not been formally confirmed. However, the last 16 amino acids do not considerably influence the sequence analysis of ORF2.

The deletional analysis (Fig. 1) suggests that ORF1 complements the mutation in WH363 indicating that a putative rubredoxin is involved in dodecane oxidation. The first rubredoxin involved in alkane oxidation by $A$. calcoaceticus was found in a culture grown on a mixture of different long chain alkanes as sole carbon source (Aurich et al., 1976). Subsequently, the corresponding rubredoxin reductase was isolated (Claus et al., 1979). These results agree well with our finding that genes encoding proteins with similarity to both enzymes are necessary for growth on long chain alkanes. Their functional requirement is also reflected by their proximity on the chromosome.

The lack of apparent promoter and transcriptional terminator structures flanking these genes suggests that they may be part of a larger operon. This has also been found for the alkane utilization genes in Ps. oleovorans, which are organized in two operons. However, the genetic organization of genes for alkane degradation must be different in ADP1, because the putative rubredoxin and rubredoxin reductase genes are located in different operons in Ps. oleovorans, whereas they are adjacent and appear to be in the same operon in ADP1 (von Beilen $e t$ al., 1992; Kok et al., 1989). Furthermore, the Ps. oleovorans alk $G$ gene, encoding rubredoxin, contains an apparent gene duplication leading to a rubredoxin with twice the molecular mass of the one from $A$. calcoaceticus. The $P_{s}$. oleovorans genes are located on the OCT plasmid, whereas the DNA analysed in this study from $A$. calcoaceticus ADP1 appears to be located on the chromosome (A. Ratajczak \& W. Hillen, unpublished). Thus, the similarities of the primary structures (see Figs 3 and 4) are not reflected in the genetic organization of these genes in both organisms. It is also remarkable to note that the rubredoxin with highest similarity to the one from $A$. calcoaceticus originates from Clostridium thermosaccharolyticum.

Many reductases, five of which are shown in Fig. 4(a), have cosubstrate binding sites in common. These are indicated in Fig. 4(b) and correspond to dinucleotide binding consensus elements typical for $\mathrm{NAD}^{+}$and $\mathrm{FAD}$ binding sites. They have been determined on the basis of sequence (Wierenga et al., 1986; Eggink et al., 1990) and structural (Karplus \& Schulz, 1987; Schierbeek et al., 1989) comparisons.

At present we do not have an explanation for the different phenotypes of WH363 on agar plates and in liquid media. We speculate that the toxicity of the alkanes (Asperger \& Kleber, 1991) may have different effects on growth in solid and liquid media. This is supported by the fact that only dodecane, the more toxic alkane compared to hexadecane, leads to the growth deficiency on solid medium. The important experimental difference may be that the alkanes are provided through the gaseous phase for growth on solid media, while they are mixed by sonication with the liquid media. Thus, it may be speculated that $A$. calcoaceticus has a more efficient defence mechanism in liquid than on solid medium. This would imply that the presumed point mutation in the rubredoxin gene of WH363 leads to a reduced activity of the encoded product. Therefore, the insertions were generated and, indeed, resulted in clear and consistent phenotypes on both media. However, these mutants may have a polar effect on the expression of any genes which may be located downstream from the sequenced region in the operon.

The insertion strains indicate clearly, that the putative rubredoxin gene is expressed, as the $\beta$-galactosidase activity in the insertion with the parallel orientation was at least 50-fold higher than in the opposite orientation. Under the conditions tested, transcription of the rubredoxin gene was constitutive and leads to a low level of mRNA as indicated by the low level of $\beta$-galactosidase.

\section{ACKNOWLEDGEMENTS}

The authors thank K. Garke for typing the manuscript. This work was supported by the Deutsche Forschungsgemeinschaft and the Fonds der chemischen Industrie.

\section{REFERENCES}

Asperger, O. \& Kleber, H.-P. (1991). Metabolism of alkanes by Acinetobacter. In The Biology of Acinetobacter, pp. 323-351. Edited by K. J. Towner, E. Bergogne-Berezin \& C. A. Fewson. New York: Plenum Press.

Aurich, H., Sorger, D. \& Asperger, O. (1976). Isolierung und 
Charakterisierung eines Rubredoxins aus Acinetobacter calcoaceticus. Acta Biol Med Ger 35, 443-451.

Ausubel, F. M., Brent, R., Kingston, R. E., Moore, D. D., Seidman, J. G., Smith, J. A. \& Struhl, K. (1989). Current Protocols in Molecular Biology, vols I \& II. New York: Greene Publishing Associates.

van Beilen, J. B., Eggink, G., Enequist, H., Bos, R. \& Withold, B. (1992). DNA sequence determination and functional characterization of the OCT-plasmid encoded alkJKL genes of Pseudomonas oleovorans. Mol Microbiol 6, 3121-3136.

Blake, P. R., Park, J.-B., Bryant, F. O., Aono, S., Magnuson, J. K., Eccleston, E., Howard, J. B., Summers, M. F. \& Adams, M. W. W. (1991). Determinants of protein hyperthermostability: purification and amino acid sequence of rubredoxin from the hyperthermophilic archaebacterium Pyrococcus furiosus and secondary structure of the zinc adduct by NMR. Biochemistry 30, 10885-10895.

Breuil, C., Shindler, D. B., Sijher, J. S. \& Kushner, D. J. (1978). Stimulation of lipase production during bacterial growth on alkanes. J Bacteriol 133, 601-606.

Claus, R., Asperger, O. \& Kleber, H.-P. (1979). Eigenschaften der Rubredoxinreduktase aus dem alkanassimilierenden Bakterienstamm Acinetobacter calcoaceticus. Z Allg Mikrobiol 19, 695-707.

Claus, R., Asperger, O. \& Kleber, H.-P. (1980). Influence of growth phase and carbon source on the content of rubredoxin in Acinetobacter calcoaceticus. Arch Microbiol 128, 263-265.

Crouse, G. F., Frischauf, A. \& Lehrach, H. (1983). An integrated and simplified approach to cloning into plasmids and single stranded phages. Methods Enzymol 101, 78-89.

Devereux, J., Haeberli, P. \& Smithies, O. (1984). A comprehensive set of sequence analysis programs for the VAX. Nucleic Acids Res 12, 387-395.

DiMarco, A. A. \& Ornston, N. (1994). Regulation of p-hydrobenzoate hydroxylase synthesis by PobR bound to an operator in Acinetobacter calcoaceticus. J Bacteriol 176, 4277-4284.

Eggink, G., Engel, H., Meijer, W. G., Otten, J., Kingma, J. \& Withold, B. (1988). Alkane utilization in Pseudomonas oleovorans. $J$ Biol Chem 263, 13400-13405.

Eggink, G., Engel, H., Vriend, G., Terpstra, P. \& Withold, B. (1990). Rubredoxin reductase of Pseudomonas oleovorans. J Mol Biol 212, 135-142.

Ehrt, S., Ornston, L. N. \& Hillen, W. (1994). RpoN $\left(\sigma^{54}\right)$ is required for conversion of phenol to catechol in Acinetobacter calcoaceticus. $J$ Bacteriol 176, 3493-3499.

Fickett, J. (1982). Recognition of protein coding regions in DNA sequences. Nucleic Acids Res 10, 5303-5318.

Hanahan, D. (1983). Studies on transformation of Escherichia coli with plasmids. $J$ Mol Biol 166, 557-580.

Hunger, M., Schmucker, R., Kishan, V. \& Hillen, W. (1989). Analysis and nucleotide sequence of an origin of DNA replication in Acinetobacter calcoaceticus and its use for Escherichia coli shuttle plasmids. Gene 87, 45-51.

Juni, E. \& Janik, A. (1969). Transformation of Acinetobacter calcoaceticus (Bacterium anitratum). J Bacteriol 98, 281-288.

Karplus, P. A. \& Schulz, G. E. (1987). Refined structure of glutathione reductase at 1.54 ̊ resolution. J Mol Biol 195, 701-729.

Kok, M., Oldenhuis, R., van der Linden, M. P. G., Meulenberg, C. H. C., Kingma, J. \& Withold, B. (1989). The Pseudomonas oleovorans alk $B A C$ operon encodes two structurally related rubredoxins and an aldehyde dehydrogenase. $J$ Biol Chem 264, 5442-5451.

Kokotek, W. \& Lotz, W. (1989). Construction of a lacZ-kanamycin- resistance cassette, useful for site-directed mutagenesis and as a promoter probe. Gene 84, 467-471.

Leahy, J. G. \& Colwell, R. R. (1990). Microbial degradation of hydrocarbons in the environment. Microbiol Rev 54, 305-315.

Meyer, J., Gagnon, J., Sieker, L. C., van Dorsselaer, A. \& Moulis, J.-M. (1990). Rubredoxin from Clostridium thermosaccharolyticum. Amino acid sequence, mass-spectrometric and preliminary crystallographic data. Biochem J 271, 839-841.

Miller, J. H. (1972). Experiments in Molecular Genetics. Cold Spring Harbor, NY: Cold Spring Harbor Laboratory.

Palmen, R., Vosman, B., Buijsman P., Breek, C. K. D. \& Hellingwerf, K. (1993). Physiological characterization of natural transformation in Acinetobacter calcoaceticus. J Gen Microbiol 139, 295-305.

Patel, R. N., Mazumdar, S. \& Ornston, L. N. (1975). $\beta$-Ketoadipate enol-lactone hydrolases I and II from Acinetobacter calcoaceticus. $J$ Biol Chem 250, 6567-6577.

Pearson, W. \& Lipman, D. (1988). Improved tools for biological sequence comparison. Proc Natl Acad Sci US A 85, 2444-2448.

Peterson, J. A., Lorence, M. C. \& Amarneh, B. (1990). Putidaredoxin reductase and putidaredoxin. J Biol Chem 265, 6066-6073.

Peterson, J. A., Lu, J.-Y., Geisselsoder, J., Graham-Lorence, S., Carmona, C., Witney, F. \& Lorence, M. C. (1992). Cytochrome P-450 terp. J Biol Chem 267, 14193-14203.

Sambrook, J., Fritsch, E. F. \& Maniatis, T. (1989). Molecular Cloning: a Laboratory Manual, 2nd edn. Cold Spring Harbor, NY: Cold Spring Harbor Laboratory.

Sanglard, D. \& Loper, J. C. (1989). Characterization of the alkane inducible cytochrome P450 (P450alk) gene from the yeast Candida tropicalis: identification of a new P450 gene family. Gene 76, 121-136.

Schierbeek, A. J., Swarte, M. B. A., Dijkstra, B. W., Vriend, G., Read, R. J., Hol, W. G. J., Drenth, J. \& Betzel, C. (1989). X-ray structure of lipoamide dehydrogenase from Azotobacter vinelandii determined by a combination of molecular and isomorphous replacement techniques. $J$ Mol Biol 206, 365-379.

Shanley, M. S., Harrison, A., Parales, R. E., Kowalchuk, G., Mitchell, D. J. \& Ornston, L. N. (1994). Unusual G + C content and codon usage in $\operatorname{catIJF}$, a segment of the ben-cat supra-operonic cluster in the Acinetobacter calcoaceticus chromosome. Gene 138, $59-65$.

Southern, E. M. (1975). Detection of specific sequences among DNA fragments separated by gel electrophoresis. J Mol Biol 98, 503-517.

White, P. J., Hunter, I. S. \& Fewson, C. A. (1991). Codon usage in Acinetobacter structural genes. In The Biology of Acinetobacter, pp. 251-257. Edited by K. J. Towner, E. Bergogne-Berezin \& C. A. Fewson. New York: Plenum Press.

Wierenga, R. K., Terpstra, P. \& Hol, W. G. J. (1986). Prediction of the occurence of the ADP-binding $\beta \alpha \beta$-fold in proteins using an amino acid sequence fingerprint. $J$ Mol Biol 187, 101-107.

Woolley, K. J. \& Meyer, T. E. (1987). The complete amino acid sequence of rubredoxin from the green phototrophic bacterium Chlorobium thiosulphatophilum strain PM. Eur J Biochem 163, 161-166.

Zylstra, J. G. \& Gibson, D. T. (1989). Toluene degradation by Pseudomonas putida F1. J Biol Chem 264, 14940-14946.

Received 21 November 1994; revised 3 February 1995; accepted 15 February 1995. 